\title{
A SURVEY AND STUDY OF TOWERKILLS AND WIND TURBINE KILLS
}

\author{
LIN, S.-C. \\ Department of Civil Engineering and Engineering Management, National Quemoy University \\ \#1 University Road, Jinning, Kinmen, Taiwan \\ e-mail: sclin@nqu.edu.tw; tel: +886-82-313-510; fax: +886-82-313-528 \\ (Received $8^{\text {th }}$ Sep 2016; accepted $1^{\text {st }}$ Dec 2016)
}

\begin{abstract}
The world is full of anthropogenic obstacles and ecological traps for wildlife but we rarely consider the possible ecological impacts on individual animals or regional ecosystems into account as designs are implemented. This research studies the impacts of electric transmission towers and wind turbines on animal casualties and behaviors. Within a one-year period, ecological surveys were conducted in areas adjacent to the Taichung Power Plant in Taiwan to analyze the interactions between the two facilities and avian collisions. Complete mechanisms of towerkill and wind-turbine kill are yet to be found, but the bird carcasses were all found next to waters especially the freshwater bodies. This high correlation may generate the conclusion that manmade structures close to water bodies are the most dangerous to birds. This conclusion may be very valuable for engineers in sitting the locations of the electric transmission towers and wind turbines.
\end{abstract}

Keywords: electric transmission tower, ecological conservation, wind farm, avian collision, Taiwan

\section{Introduction}

Humankind has completely dominated nature with advanced technologies. Development and construction have been carried out based on human needs and desires, leading to unprecedented anthropogenic destruction of existing ecosystems. According to estimations by biologist Edward O. Wilson (1989), approximately 10,000-15,000 species are facing extinction every year. Every day, 34 species disappear because of delays in conservation. There will be continuous and rapid deterioration of biodiversity, ecological integrity, and ecological health in the future globally. Ecological conservation is an imperative undertaking for the world. Along with social progress, ecological conservation will gradually become the popular consensus. Human rights and animal rights will gain traction at the same time, and humanity cannot exclude itself from the global ecosystem. Each species has its niche in the ecosystem, which is particularly true for birds. They are not only important members of ecosystems but also an indispensable element of social aesthetics and an indicator of environmental health. However, there are occasionally reports of killed birds, not only from direct human hunting, but also from anthropogenic facilities that have indirectly led to innumerable deaths. Many towers can attract birds or cause birds in flight to have blind collisions, which may be an ecological trap for many birds (especially high-flying migratory birds). What class of birds is most affected by towers and power lines? What is the impact on the number of species groups? These questions currently have not been systematically addressed.

According to research, human activities (mainly hunting) and anthropogenic facilities cause 200 million bird deaths annually, among which $61 \%$ is from hunting, $29 \%$ from traffic accidents involving animals, 3\% from bird collisions with buildings, and $7 \%$ for other reasons (Banks, 1979). In general, the development of engineering design and construction is based on human subjective norms. Structures such as bridges, 
buildings, parks, green spaces, all sorts of towers, and so on may act as biological parks or animal traps at different levels. High-rise structures are an illustrative example. There had been observations of collisions between birds and towers since the 1940s in North America (towerkill.com). When there is dense fog or low atmospheric clouds at night, migratory birds are often attracted to the flashing lights of the tower and fly around it. Most bird deaths from towers occur when the birds cannot sense the presence of the power line. In the future, there will be increasing numbers of cell phone towers and wind turbines constructed, which may further affect the migration of birds at night. Electric transmission towers, telecom towers, bridges, and their attached cables are all obvious bird traps. In particular, power lines often stop birds mid-flight, lethally entangling them. Such cases are too numerous to name (Bevanger and Brøseth, 2004). In the United States of America in the 1970s, there were 1.3 million bird deaths each year caused by 1,010 TV towers (Banks, 1979). In addition, in the 25 years after 1960, there were more than 42,000 dead birds found around a single tower in Tallahassee, Florida (Crawfowrd and Engstrom, 2000). Hence, towers in certain locations can cause an alarmingly large number of bird casualties. However, after 28 years of investigation, the same researchers found that reducing the height of the tower can effectively reduce bird casualties (Crawford and Engstrom, 2001). Towers with a height of less than 61 meters pose no discernible danger to birds (Kerlinger, 2000).

There are two modes of mortality from bird collision with towers or power lines (towerkill.com). The first is from direct impacts due to the inherently poor eyesight of birds, which is termed "blind collision." Certain fast-flying birds, such as waterfowl or shorebirds, may experience death by blind collision because they cannot see the towers or cables when there is daytime fog. Around a TV tower in Topeka, Kansas, in the USA, there were 2,808 deaths of birds from 9 species over a 4-night period (Ball et al., 1995). The other mode of death is collision death due to the attraction of the lights on the tower. Collision deaths would be more likely if a tower does not have a flashing light at night. The color of the flashing light emanating from the tower also has a significant effect on the flight path of birds. A red flashing light is more likely to create a nonlinear flight path for birds than a dazzling white light, or no light at all (Gauthreaux and Belse, 2006). Therefore, birds may be more sensitive to a red flashing light. However, another study (Evans et al., 2007) found that a blue, green, or white light was more effective in attracting birds than a red light when there is low cloud cover, which contradicts the previous study. Nonetheless, two other studies (Longcore and Gauthreaux, 2008; Gehring et al., 2009) suggested that avoiding using a red light on towers could help deter bird collisions, which seemed to imply that a red light might cause birds to fly closer to towers. However, in areas with mist, smoke, or high moisture, there will be a diffusion phenomenon due to the effect of light passing through the water particles, which may form a light source to guide the birds to fly and gather. As a result, some birds may die from mistakenly hitting the cables in circling flight. Early research found that migrating birds often circle around towers because they are attracted to the flashing lights on the towers (Graber, 1968). If the flashing lights on the tower were turned off, the circling birds near the tower would disperse (Cochran and Graber, 1958). Hence, a flashing light indeed attracts birds.

Weather is also another important factor for bird collision. The diffusion of the tower light by water particles in clouds and fog may cause the migrating birds to linger (Avery et al., 1976). Low clouds may also cause birds to circle around the tower (Larkin and Frase, 1988). The above phenomena are all due to the comprehensive effects of water 
particles and light. Moreover, the insulating wires of the tower are often places for birds to build their nests, and they may become conductive on damp or rainy days, thereby killing the birds. Towers on ridges, or those that are especially tall, are flight obstacles and are thus easy collision targets for birds, leading to their deaths (Longcore and Gauthreaux, 2008).

There have been no documented cases of bird collisions with wind turbines in Taiwan (Shi et al., 2008). However, the numbers of Charadriiform waterfowl may be reduced by the wind turbines, which may cause their main flight path to move far away from the wind turbines (Shi and Cheng, 2008). The presence of wind turbines changes landscape characteristics and reduces the number of local birds. In the same way, these changes probably lead to collisions with migrating birds at night, even though there are no actual descriptions of such events in Taiwan. It is necessary to conduct detailed investigation in order to clarify whether towers and wind turbines directly kill birds. This study examined bird deaths from transmission towers and wind turbines near the Taichung Power Plant in Taiwan. The results should clarify the effects of such anthropogenic structures on bird species and their migratory patterns, sum up the main factors, and determine what steps to take to fix the problem.

\section{Scope and method of the study}

Several studies have been performed to investigate bird collisions with transmission towers and wind turbines in Taichung, Taiwan. No collision events were found even in systematic investigations (Shi and Cheng, 2008; Shi et al., 2008), which may be attributable to low survey frequency or insufficient duration. Other reasons may be that bird remains may be removed or may be scavenged and eaten by other animals. Especially in the case of bird collisions with towers and wind turbines near water bodies, the carcasses may fall into the water where they cannot be collected. Therefore, the real impact can be studied only through intensive, long-term investigation.

Taichung Power Plant and the Chang Bin coastline at Longjing Township in Taichung, Taiwan were selected as investigation site. This area is an estuary of Choshui River and an important part of the ecological protection zone, which is located along the migration route of birds. The coast of Changhua (Chang Bin coastline) is located in the center of the East Asia-Australia migration path and is a wetland of international importance. Millions of birds move back and forth between the Northern and Southern hemispheres every year. However, there are densely distributed power transmission towers and wind turbines in this area. The tower density may be the highest in Taiwan, so it is a very suitable place to investigate bird collisions with high-rise anthropogenic structures. Hence, the Taichung Power Plant and the Chang Bin coastal areas were chosen as the survey areas.

This study focused on the transmission towers of the Taichung Power Plant (Fig. 1) and the wind turbines in the coastal areas of Changhua coast. The plan was to conduct field studies on a weekly basis for 1 year to better understand the real causes of bird collisions and number casualty distributions. There are 6 groups of transmission lines spreading out from the Taichung Power Plant (Fig. 2). There are also hundred of wind turbines located in nearby coastal areas in Chang Bin coastline (Fig. 3). The tower bases can be divided into 3 levels of accessibility: (1) those that can be directly accessed (A type); (2) those that can be observed only through a telescope (B type); and (3) those that are neither accessible nor observable (C type). The A-type towers were marked and 
surveyed on a weekly basis. The researchers directly accessed the base of these towers and searched for bird carcasses within a $20 \mathrm{~m}$ radius of the base. All dead bird carcasses were picked up and their location noted. After the preliminary identification and recording, the carcasses were brought back to laboratory for further identification. Since most of the wind turbines were accessible, the same process was also used for surveying bird carcasses around them.

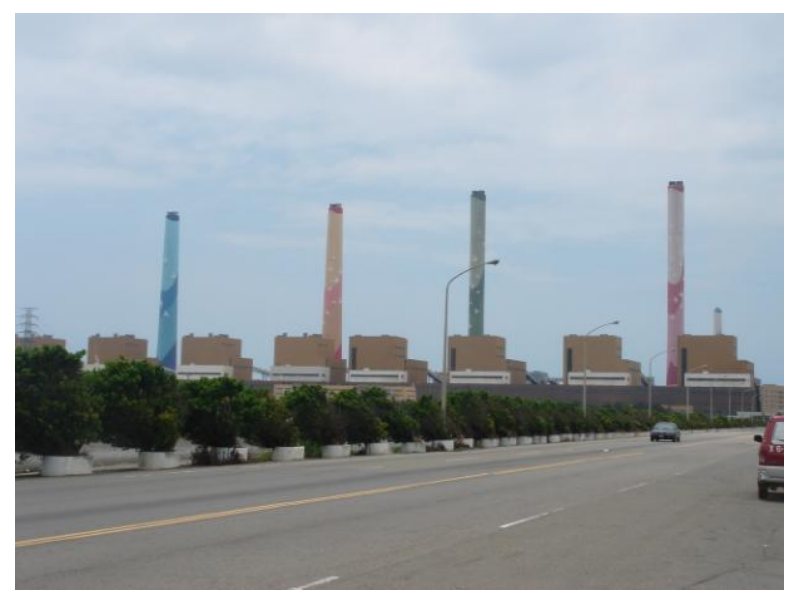

Figure 1. Taichung Power Plant

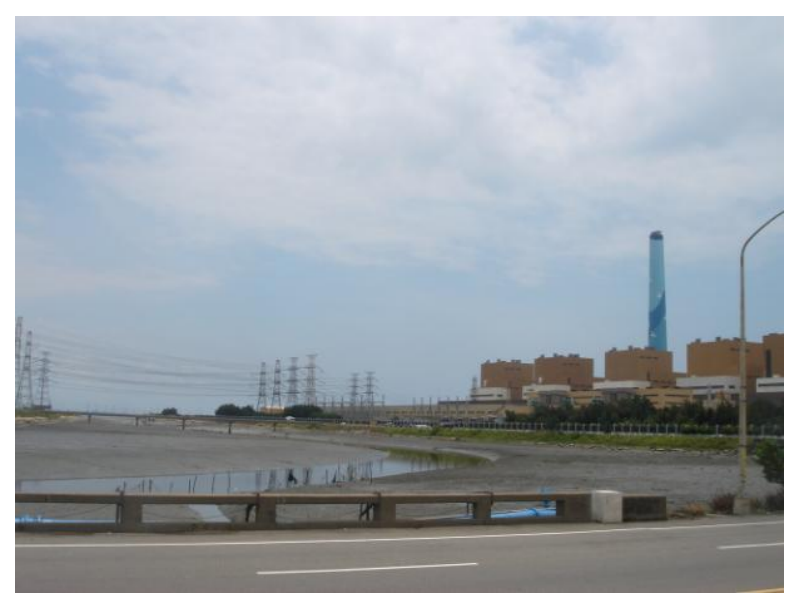

Figure 2. Tower cables to external connections

After a preliminary walking survey on July 20, 2009, the research team decided to investigate west 4 groups of towers and nearest wind turbines near the power plant. This investigation consisted of 3 stages, as described below.

Stage 1: During the period from August 1, 2009 to September 15, 2009, a preliminary investigation was conducted daily by researchers on 30 transmission towers and 30 wind turbines. The results were only for reference purposes since the survey range was different from those used in Stage 2 and Stage 3.

Stage 2: The survey was restarted on December 26, 2009 and lasted until May 16, 2010. The survey range was increased to 31 towers and 35 wind turbines that were 
investigated and analyzed on a weekly basis (always on weekends). There were 21 surveys in 142 days.

Stage 3: This stage lasted from February 18, 2012 to February 17, 2013 with the same survey range as in Stage 2 . The survey was also done on a weekly basis, for a total of 52 times in 366 days.

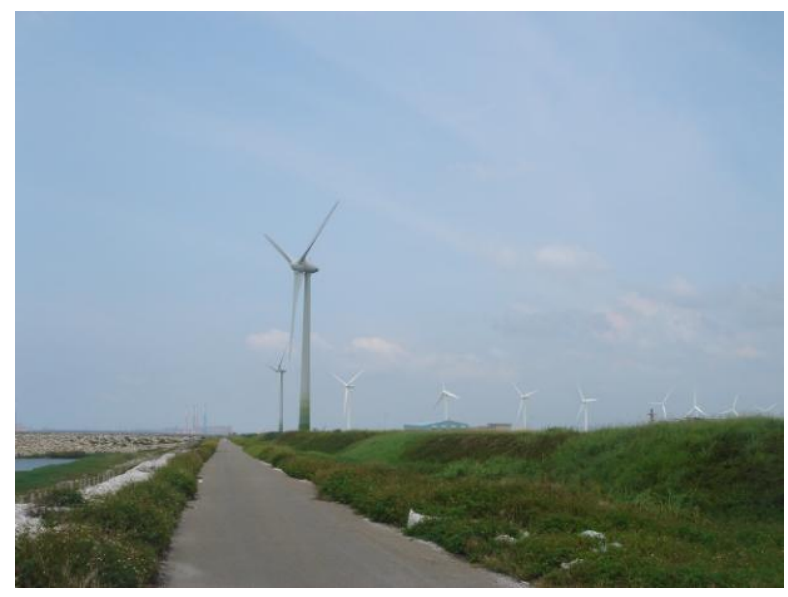

Figure 3. Wind power generation facilities in coastal areas in Chang Bin coastline

\section{Investigation results}

Taichung Power Plant is located between the Gaomei wetlands and Tatu estuary wetlands, both with abundant bird populations. The wind turbines at Chang Bin are located south of the Tatu estuary and extend for tens of kilometers southward along the Chang Bin coastline, and they provide a portion of the electric power generation in the center area. In this study, 31 towers near the Taichung Power Plant and 35 wind turbines surrounding Chang Bin Industrial Zone were chosen for the investigation of bird collisions. The study was divided into 3 stages, with Stage 3, the main study, being systematic and complete.

\section{Three-stage investigation}

Stage 1: There were 31 surveys from August 1, 2009 to September 15, 2009. A total of 5 bird carcasses were collected in this period, and their locations and species are shown in Table 1. All carcasses were found under the transmission towers where are located in land but outside the survey areas of stages 2 and 3. Stangely, no bird carcasses were spotted under wind turbines. Because this is the first survey undertaking, the carcasses were cummulated for long time and are mostly quite decayed, such that the number of carcasses is relatively higher comparing with stage 2 and 3 . This can be considered to be clean the carcasses for the next surveys. The above results should only be used as a reference, owing to the presence of scattered surveys.

Stage 2: The survey range between December 26, 2009 and May 16, 2010 is as shown in Figs. 36 and 37. The collected bird carcasses around the transmission towers are listed in Table 2, while the bird carcasses near wind turbines are shown in Table 3. 
Table 1. Details of the bird carcasses around the transmission towers in Stage 1

\begin{tabular}{ccc}
\hline Date & Location & Species \\
\hline 2009-08-02 & $\begin{array}{c}\text { Outside the investigation } \\
\text { area of Stage 3 }\end{array}$ & Sparrow (Passer montanus) \\
\hline 2009-08-12 & $\begin{array}{c}\text { Outside the investigation } \\
\text { area of Stage 3 }\end{array}$ & $\begin{array}{c}\text { Golden turtle dove (Streptopelia } \\
\text { orientalis) }\end{array}$ \\
\hline 2009-08-14 & $\begin{array}{c}\text { Outside the investigation } \\
\text { area of Stage 3 }\end{array}$ & Sparrow \\
\hline 2009-08-27 & $\begin{array}{c}\text { Outside the investigation } \\
\text { area of Stage 3 }\end{array}$ & Sparrow \\
\hline 2009-09-04 & $\begin{array}{c}\text { Outside the investigation } \\
\text { area of Stage 3 }\end{array}$ \\
\hline
\end{tabular}

Table 2. Details of the bird carcasses around the transmission towers in Stage 2

\begin{tabular}{cccc}
\hline Date & Location & Species & Figure Number \\
\hline $2009-12-27$ & No. 26 & $\begin{array}{c}\text { Common moorhen (Gallinula } \\
\text { chloropus) or } \\
\text { White-Bellied Crake } \\
\text { (Amaurornis phoenicurus })\end{array}$ & 4,5 \\
\hline $2010-01-10$ & No. 31 & $\begin{array}{c}\text { Little egret } \\
(\text { Egretta garzetta })\end{array}$ & 6,7 \\
\hline $2010-05-16$ & No. 7 & Heron (Ardea cinerea) & 8,9 \\
\hline
\end{tabular}

Table 3. Details of the bird carcasses around the wind turbines in Stage 2

\begin{tabular}{cccc}
\hline Date & Location & Species & Figure Number \\
\hline $2009-12-26$ & No. 34 & $\begin{array}{c}\text { Painted snipe (Rostratula } \\
\text { benghalensis) }\end{array}$ & 10,11 \\
\hline $2009-12-26$ & No. 34 & duck or crow & 12,13 \\
\hline $2009-12-27$ & No. 21 & Little swift (Apus affinis) & 14,15 \\
\hline $2010-03-13$ & No. 34 & Little egret & 16,17 \\
\hline $2010-04-11$ & No. 34 & Heron (Ardea cinerea) & 18,19 \\
\hline $2010-04-25$ & No. 33 & $\begin{array}{c}\text { Yellow-head fantail warbler } \\
\text { (Cisticola exilis) }\end{array}$ & 20,21 \\
\hline
\end{tabular}

Stage 3: The survey ran between February 18, 2012 and February 17, 2013 in the same locations as in Stage 2. The bird carcasses collected around the transmission towers and the wind turbines are listed in Tables 4 and 5, respectively.

Table 4. Details of the bird carcasses around the transmission towers in Stage 3

\begin{tabular}{cccc}
\hline Date & Location & Species & Figure number \\
\hline $2012-02-18$ & No. 10 & Dove $($ Columba $)$ & 22,23 \\
\hline $2012-05-20$ & No. 16 & Dove & 24,25 \\
\hline $2012-10-07$ & Between No. 10 and No. 12 & Grey wagtail (Motacillidae) & 26,27 \\
\hline $2012-10-07$ & Between No. 10 and No. 12 & $\begin{array}{c}\text { Pearl neck cushat } \\
\text { (Streptopelia chinensis) }\end{array}$ & 28,29 \\
\hline
\end{tabular}




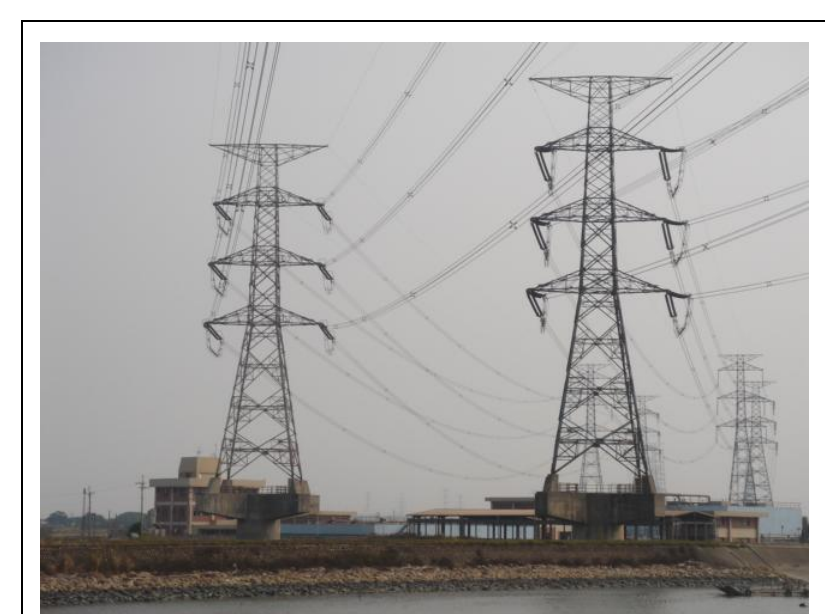

Figure 4. No. 26 tower (right side)

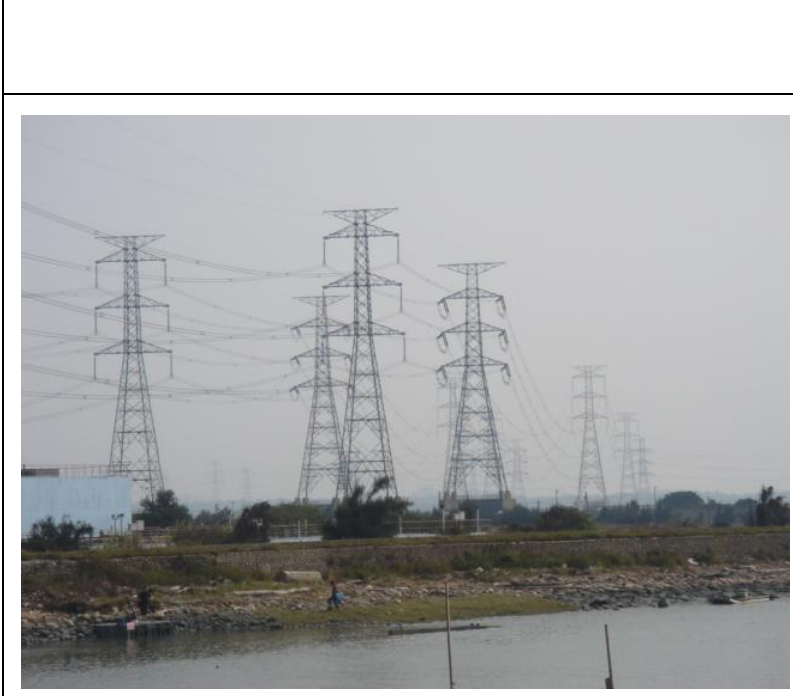

Figure 6. No. 31 tower (the second from the left)

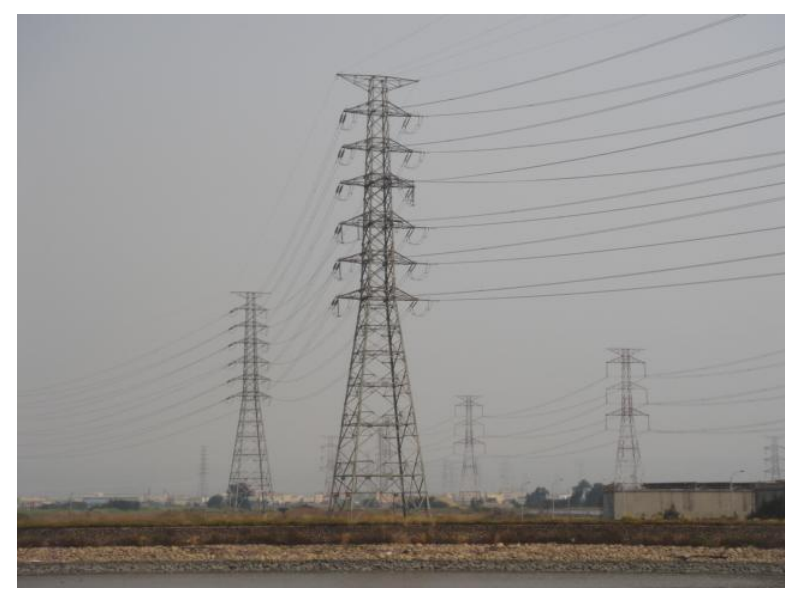

Figure 8. No. 7 tower (the second from the left)

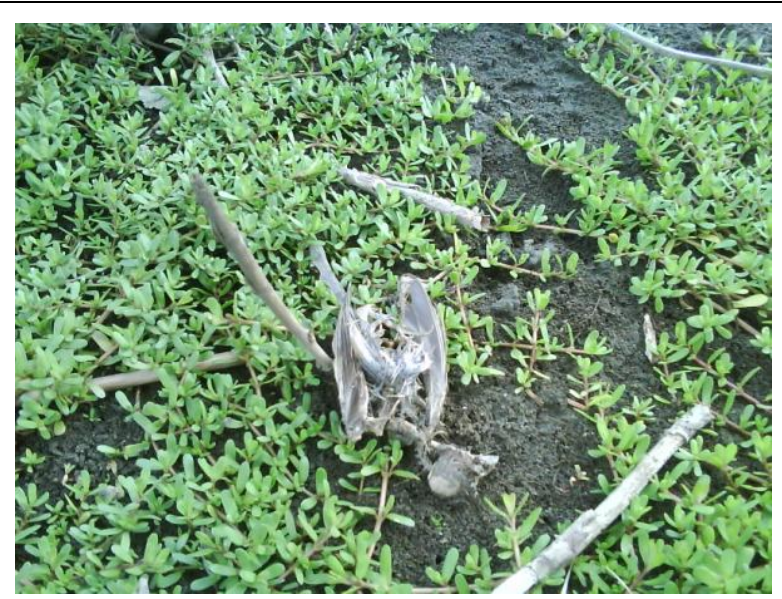

Figure 5. The common moorhen (or white-bellied crake) at the No. 26 tower

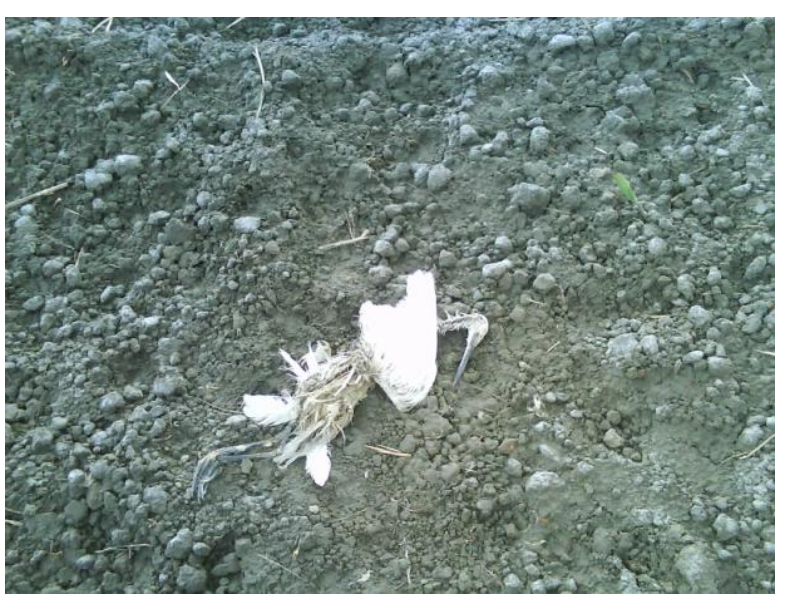

Figure 7. The little egret at the No. 31 tower

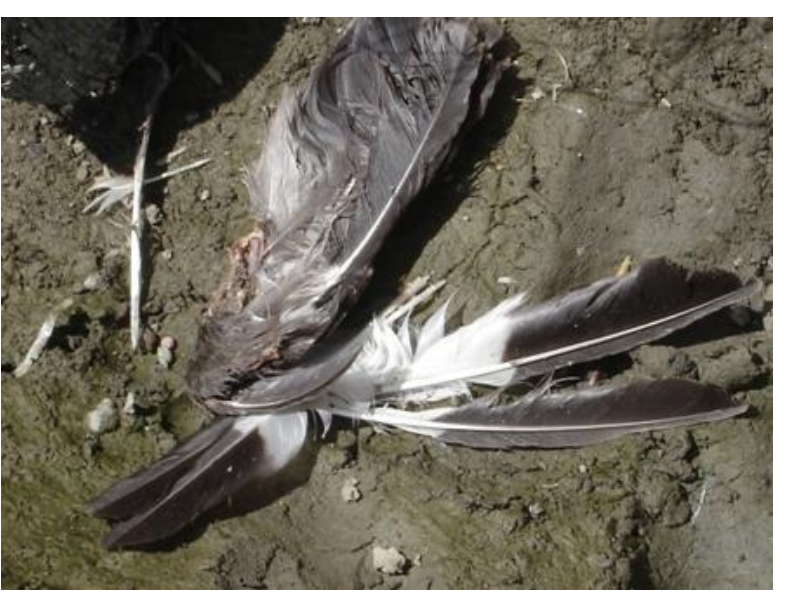

Figure 9. The heron at the No. 7 tower 


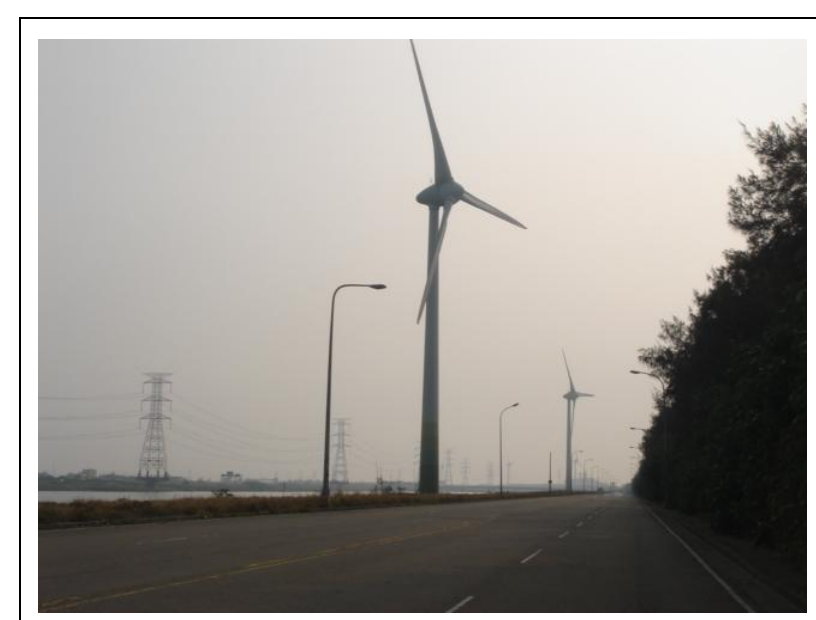

Figure 10. No. 34 wind turbine

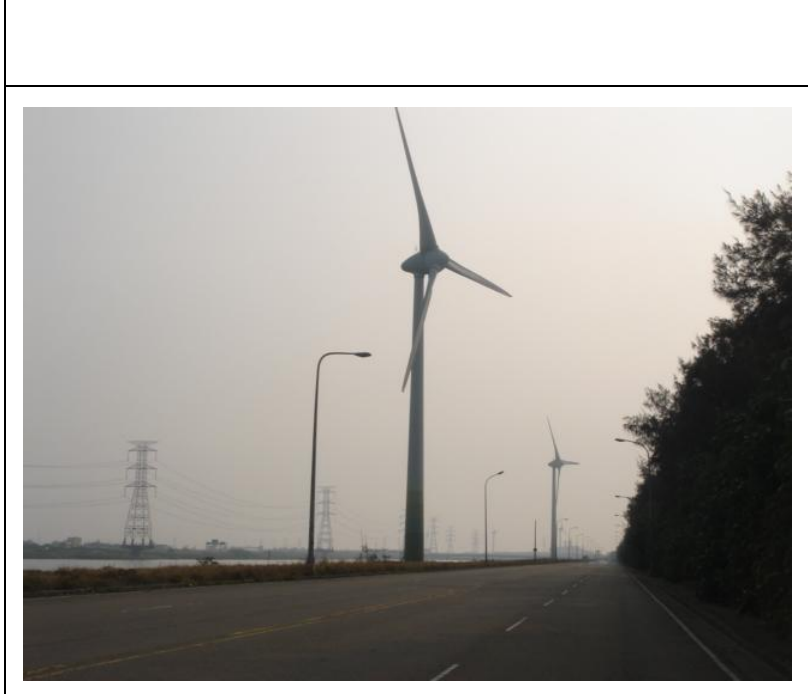

Figure 12. No. 34 wind turbine

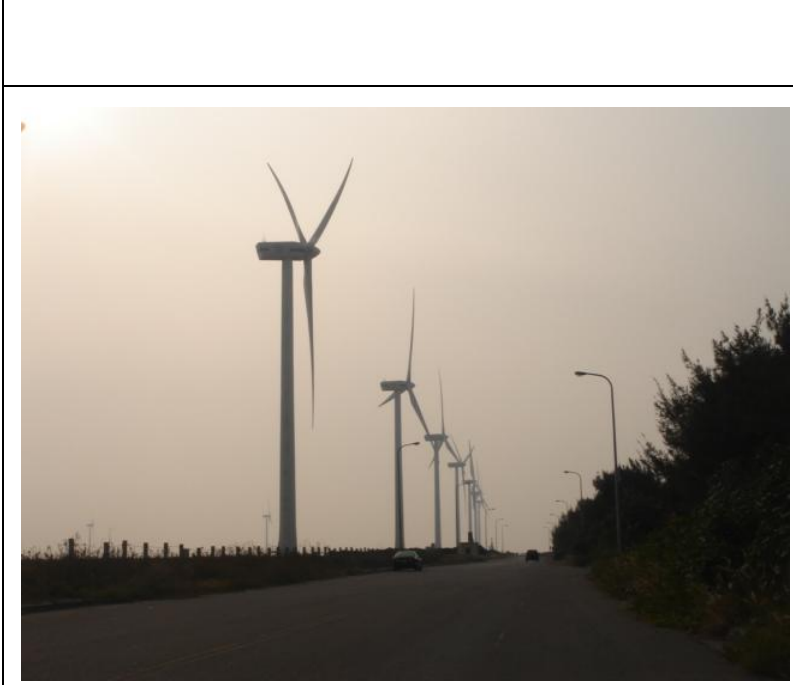

Figure 14. No. 21 wind turbine

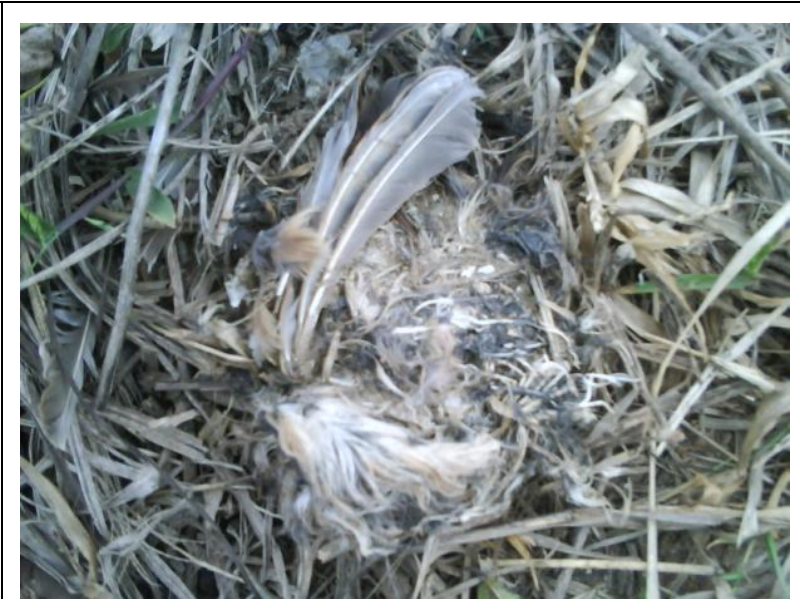

Figure 11. The painted snipe at the No. 34 wind turbine

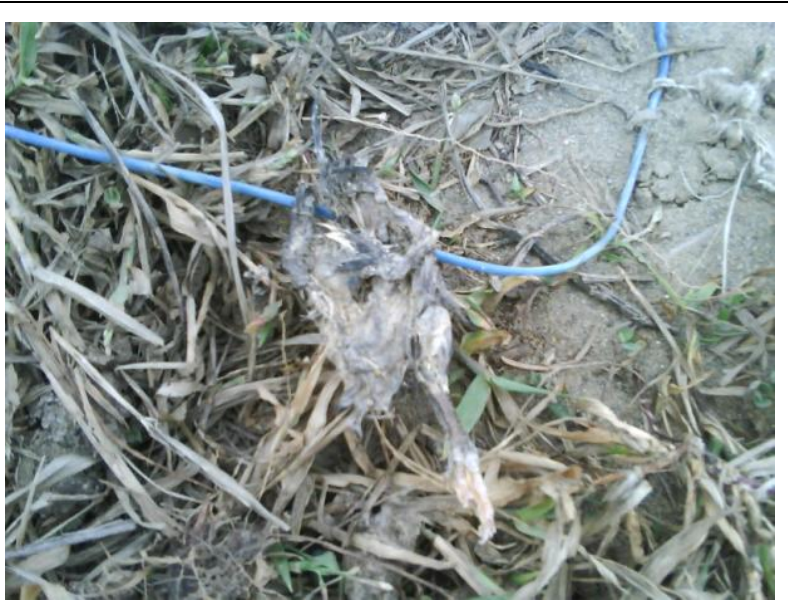

Figure 13. Duck or crow at the No. 34 wind turbine

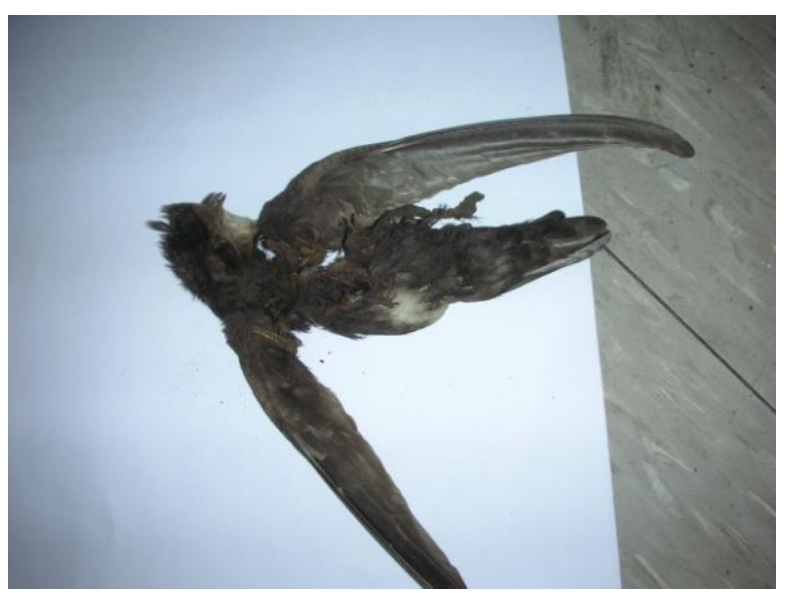

Figure 15. The little swift at the No. 21 wind turbine 


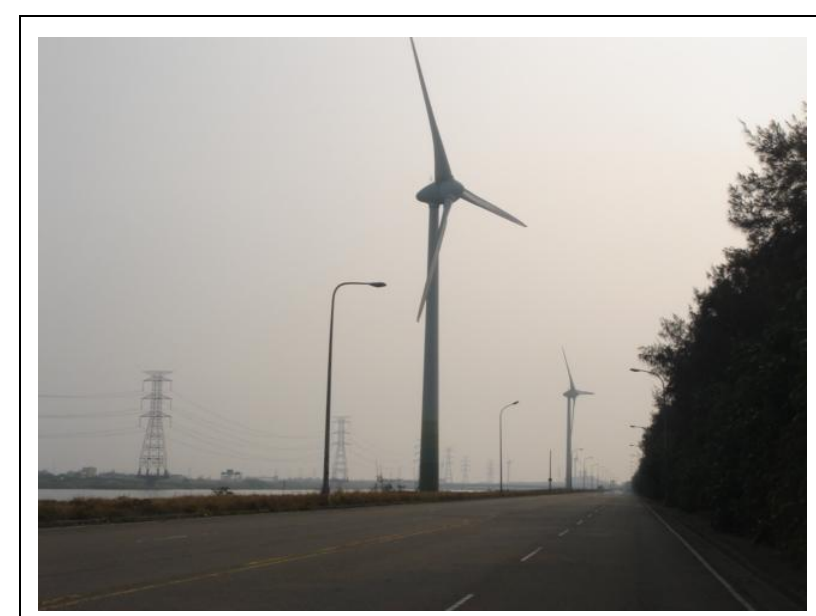

Figure 16. No. 34 wind turbine

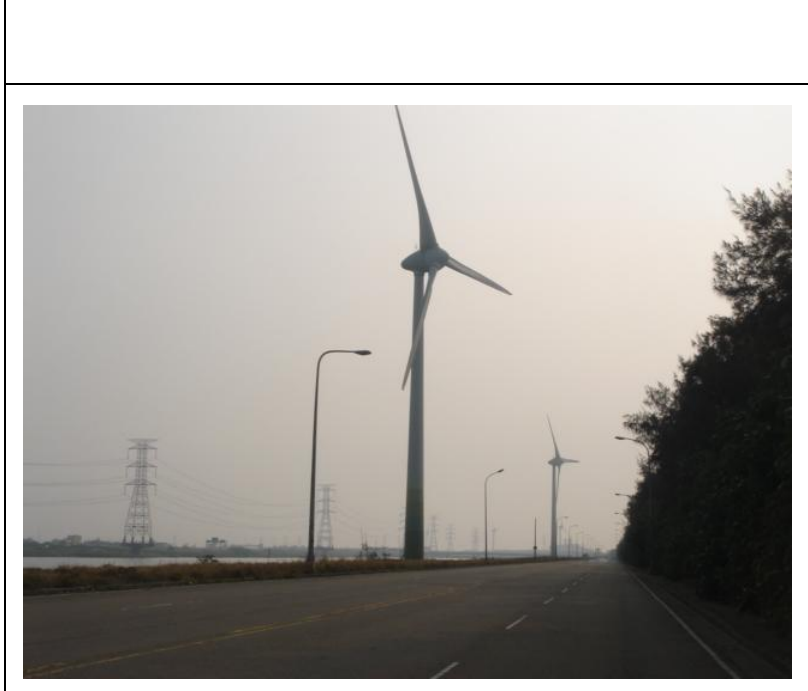

Figure 18. No. 34 wind turbine

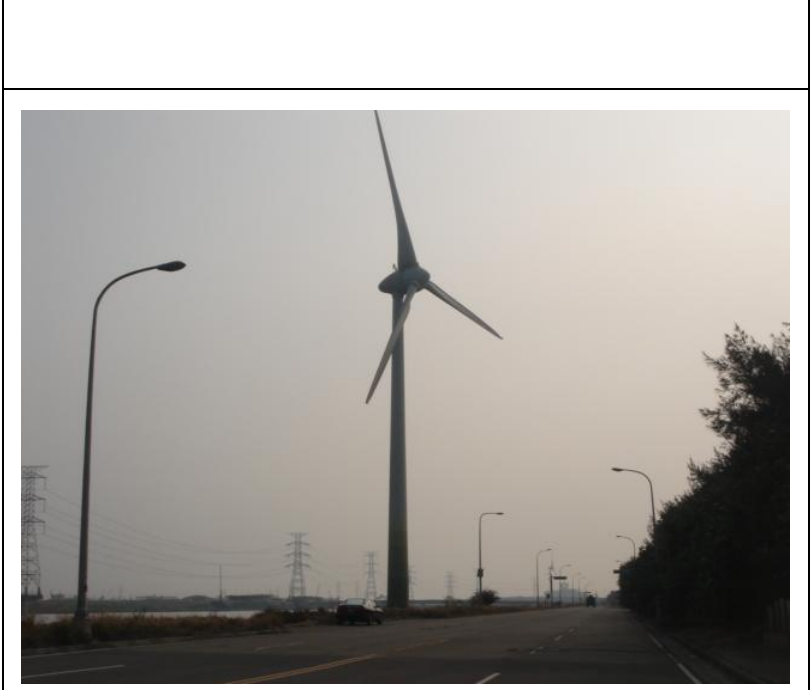

Figure 20. No. 33 wind turbine

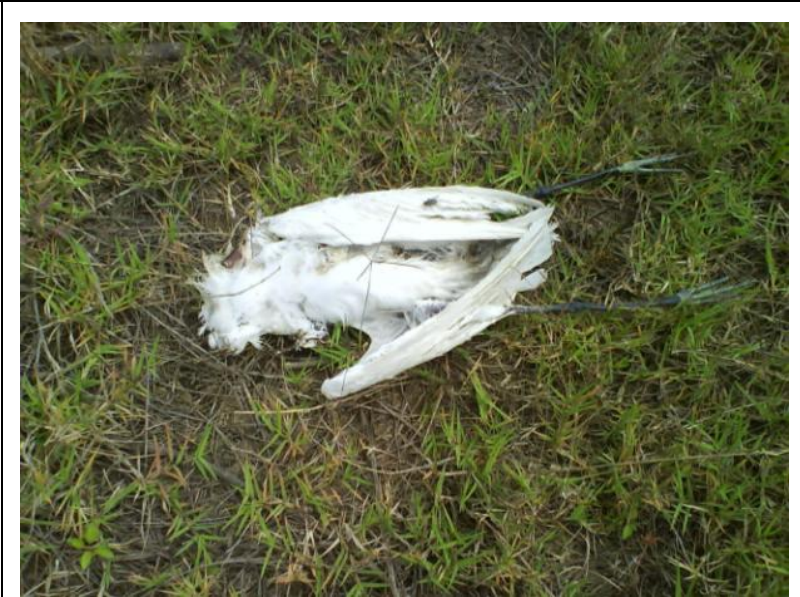

Figure 17. The little egret at the No. 34 wind turbine

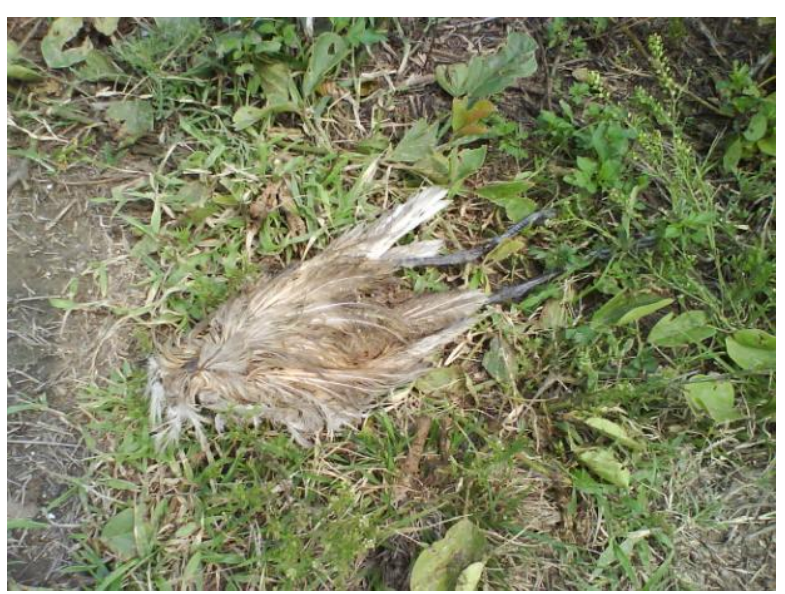

Figure 19. The heron family carcass at the No. 34 wind turbine

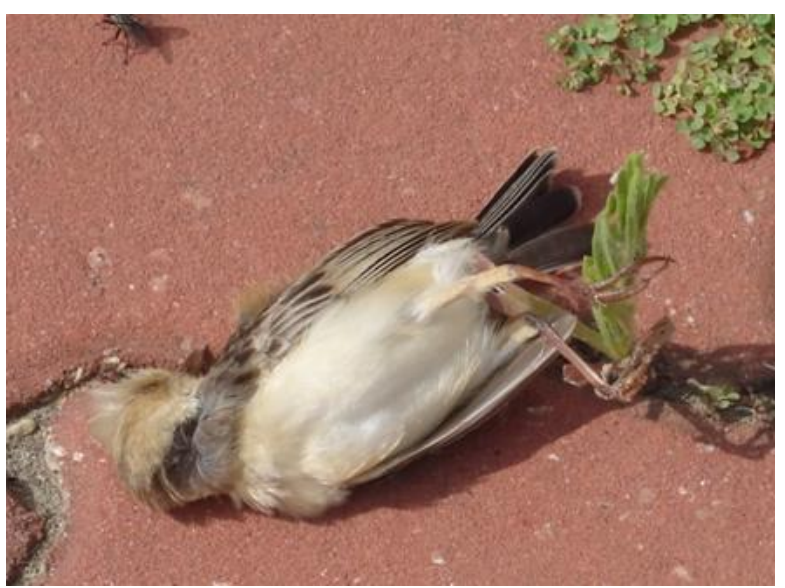

Figure 21. The yellow-head fantail warbler at the No. 33 wind turbine 


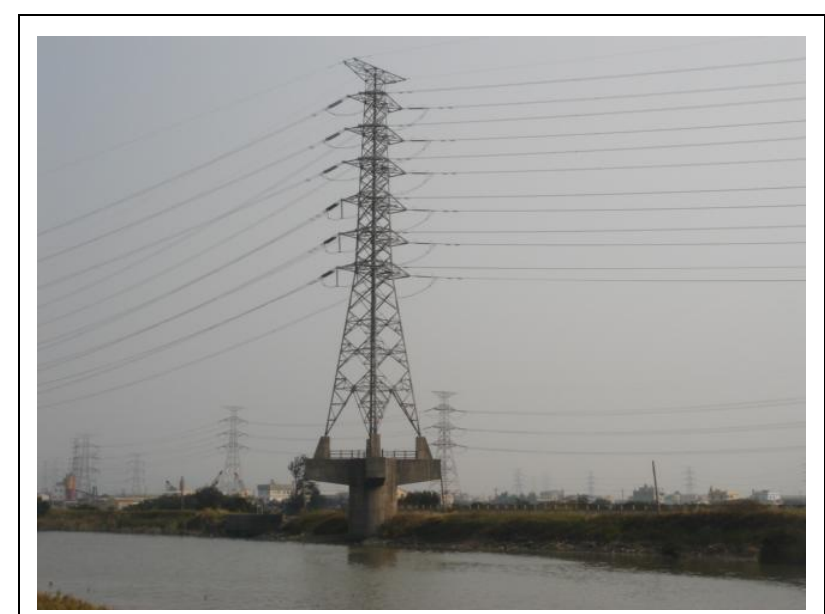

Figure 22. No. 10 tower

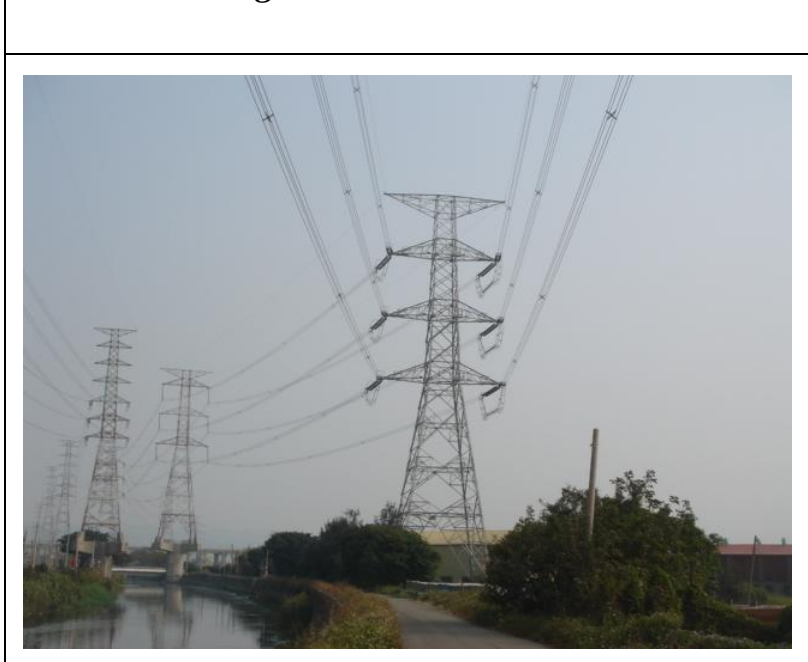

Figure 24. No. 16 tower

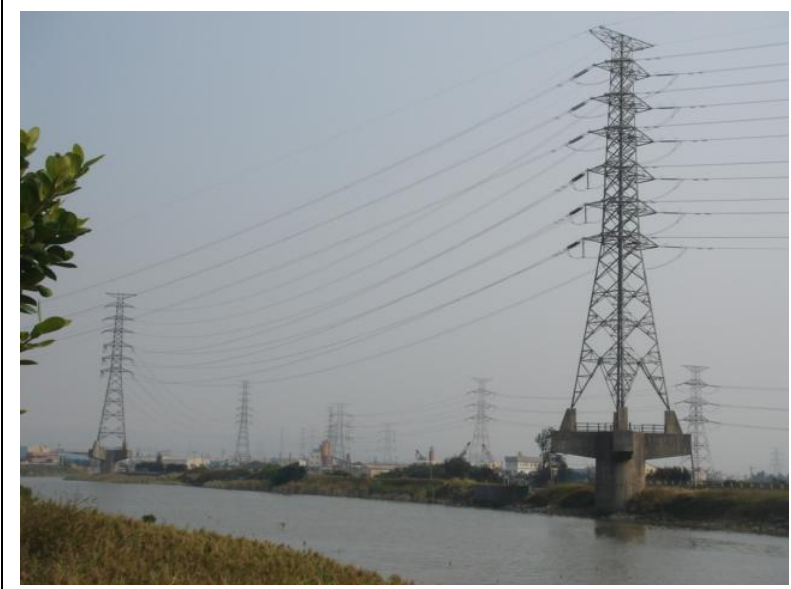

Figure 26. No. 10 and No. 12 towers

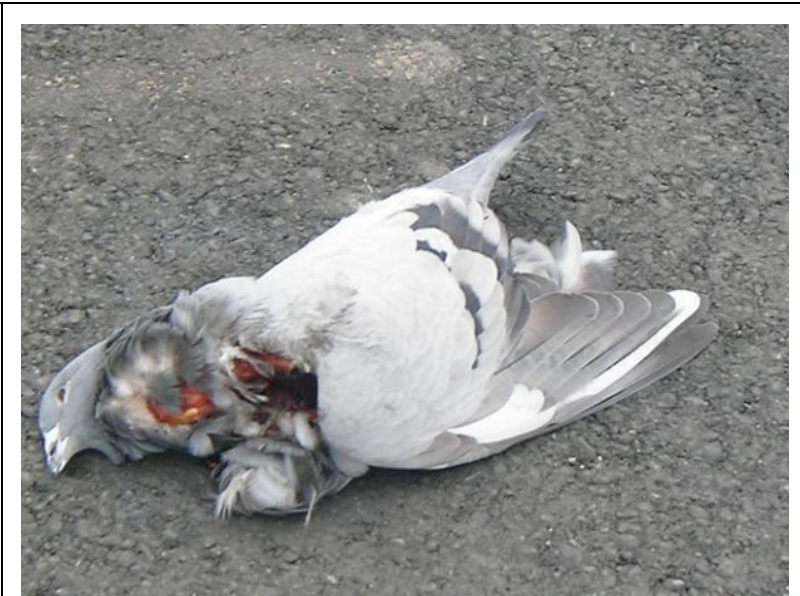

Figure 23. The dove near the No. 10 tower

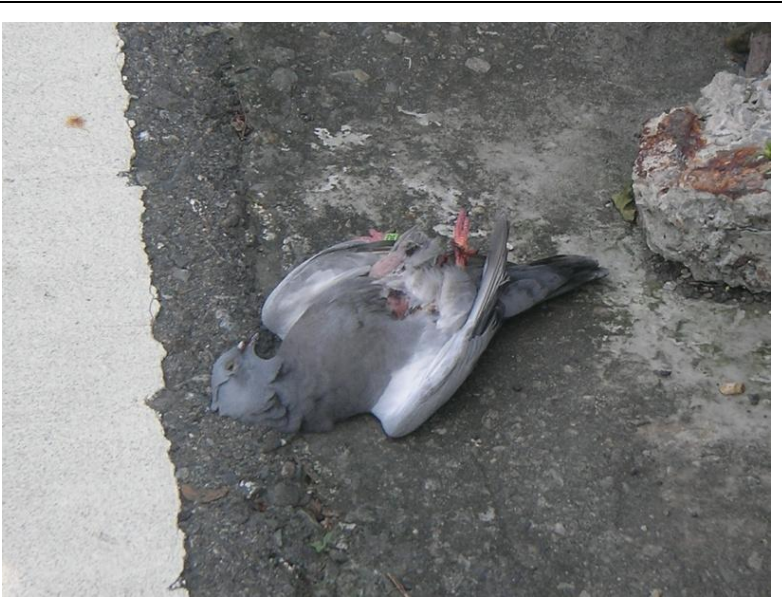

Figure 25. The dove at the No. 16 tower

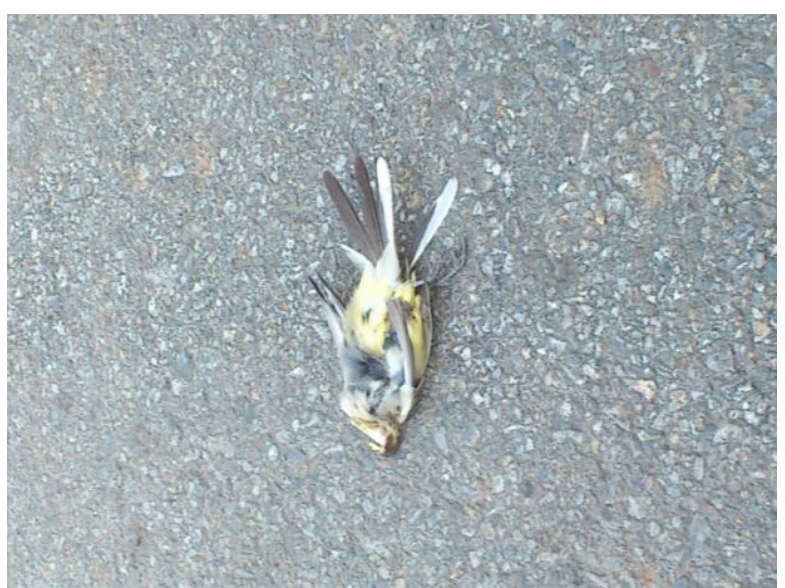

Figure 27. The grey wagtail between the No. 10 tower 


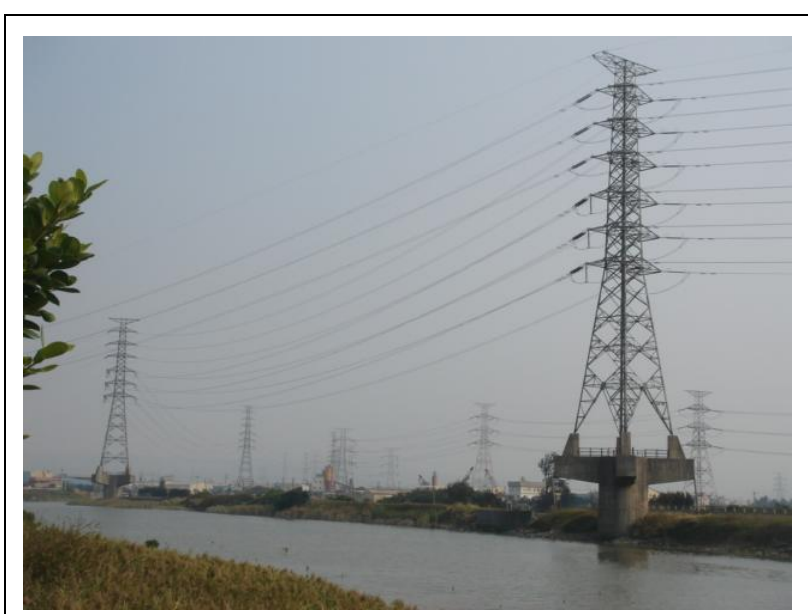

Figure 28. No. 10 and No. 12 towers

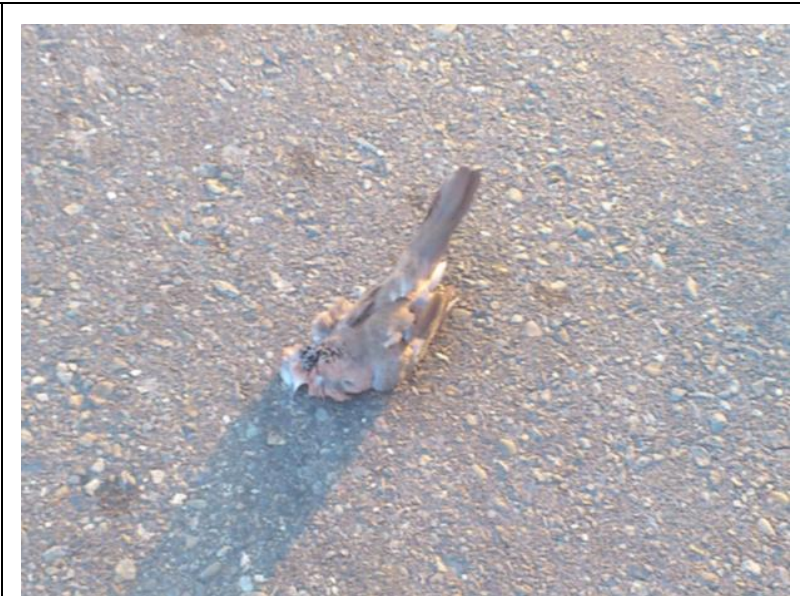

Figure 29. The pearl neck cushat beside the No. 12 tower

Table 5. Details of the bird carcasses around the wind turbines in Stage 3

\begin{tabular}{cccc}
\hline Date & Location & Species & Figure Number \\
\hline $2012-03-24$ & No. 21 turbine & Lark (Alauda gulgula) & 30,31 \\
\hline $2012-03-24$ & No. 38 turbine & Egret (Ardea alba) & 32,33 \\
\hline $2012-05-20$ & No. 38 turbine & Little swift & 34,35 \\
\hline
\end{tabular}

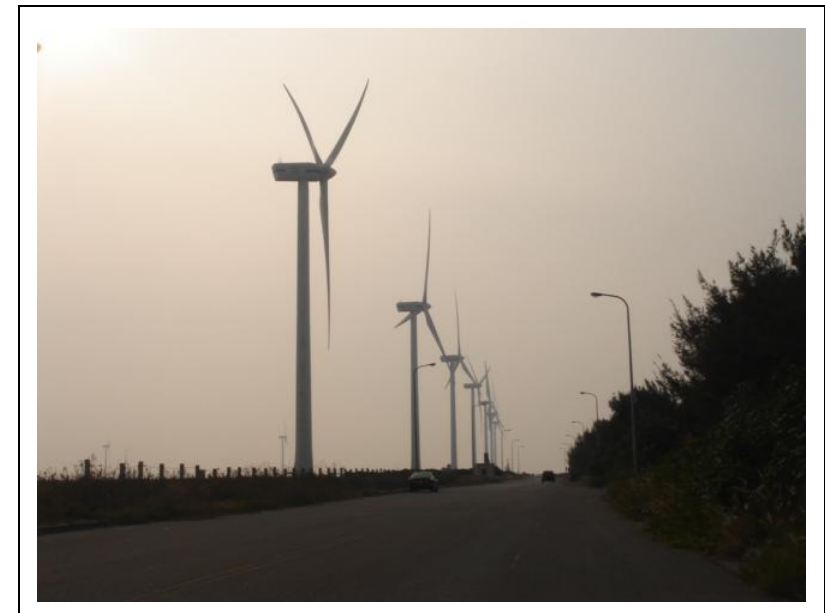

Figure 30. The first turbine is No. 21

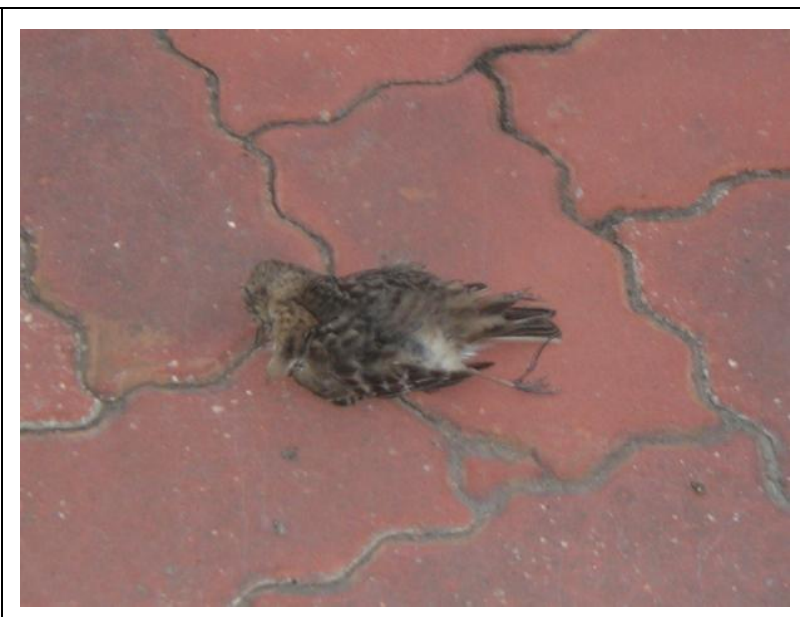

Figure 31. The lark carcass at the No. 21 turbine 


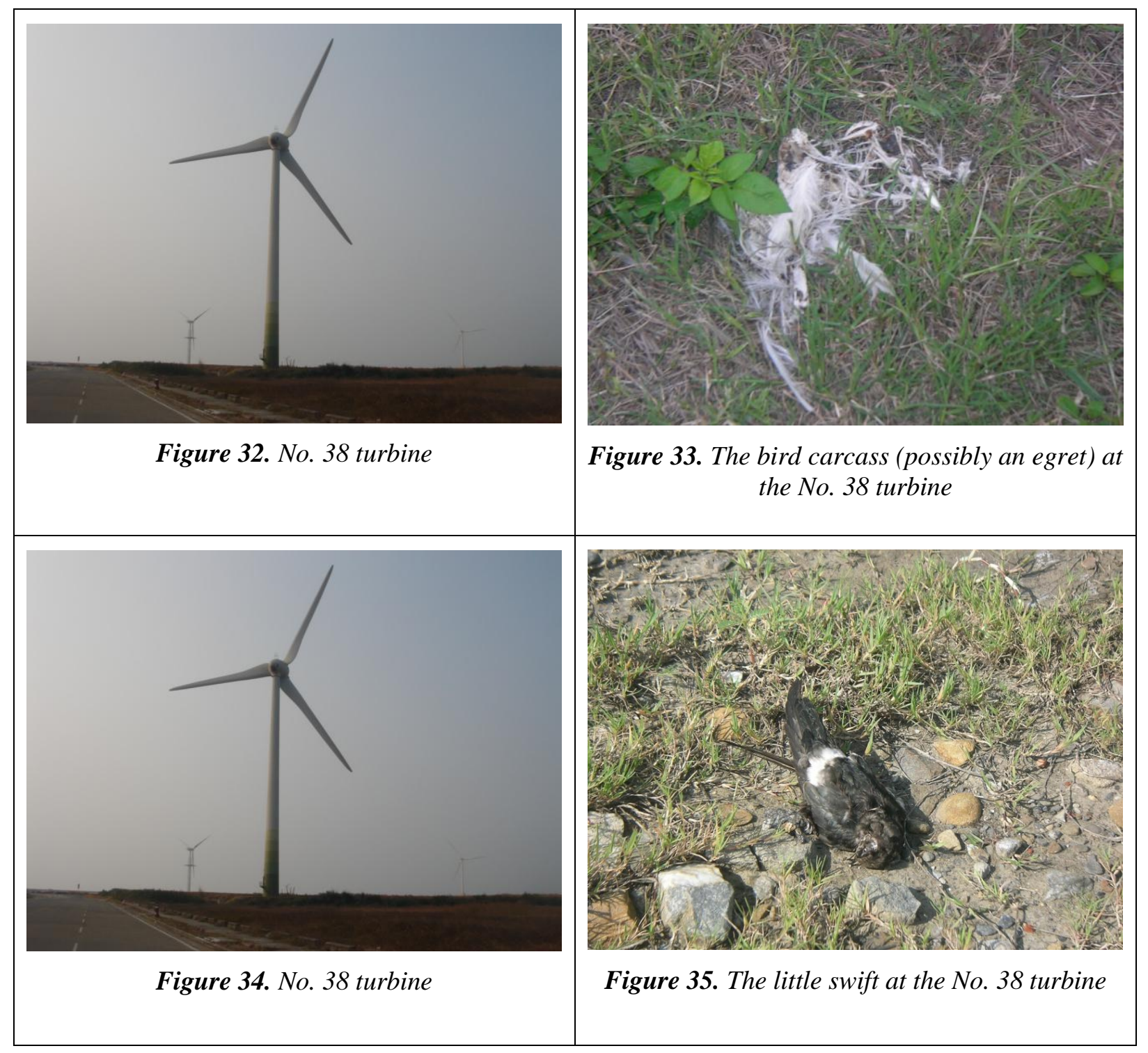

\section{Consolidated results}

A total of 9 bird carcasses were collected in Stage 2, and 7 were collected in Stage 3. Their distributions are shown in Figs. 36 and 37. Despite the small number, there was an obvious impact on the landscape and concentration of the bird collisions. For the transmission towers, all the collected bird carcasses were close to the freshwater river, while the bird collisions with the wind turbines were concentrated below the No. 34 turbine (4) and the neighboring No. 33 turbine (1). It is necessary to address the phenomenon of the concentrated bird collisions with an in-depth discussion.

\section{Bird-collision analysis}

Since no bird collision event was directly witnessed by the researchers, it is hard to know the exact situations or the modes of the collision with towers and wind turbines. However, it was estimated that the collected bird carcasses were less than the real number due to the weekly survey frequency. Between the surveys, bird carcasses might 
have been blown away by the wind, removed, taken away and eaten by wild dogs or other animals, or fallen into the water. The mechanisms of bird strikes with electric transmission towers and wind turbines are still inferable based on surveys and relevant literature, as described below.

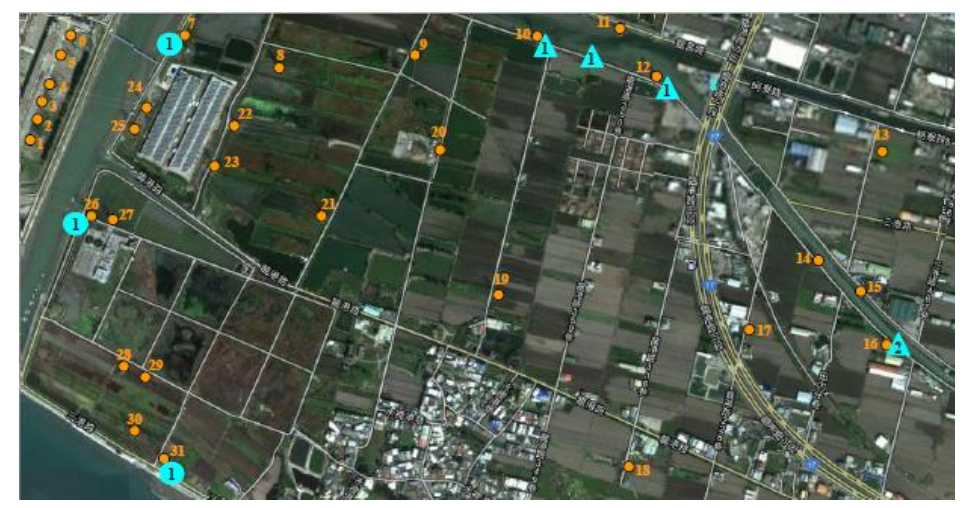

Figure 36. The distribution map of bird carcasses around the transmission towers where the symbols $\bigcirc$ and $\triangle$ stand for the survey results in Stage 2 and Stage 3, respectively. The numbers inside the symbols are the counts of the bird carcasses.

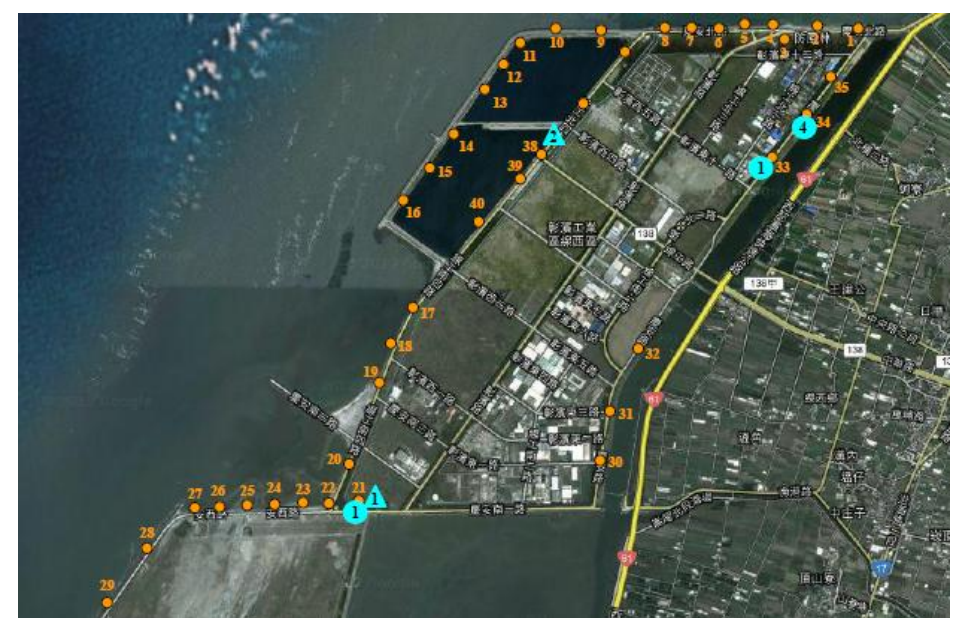

Figure 37. The distribution map of bird carcasses around the wind turbines where the symbols 0 and $\Delta$ stand for the survey results in Stage 2 and Stage 3, respectively. The numbers inside the symbols are the counts of the bird carcasses.

\section{Transmission towers}

A total of 9 bird carcasses were collected in the 21 surveys in Stage 2, with 3 around the transmission towers and 6 around the wind turbines. There were varied bird species, and it was difficult to summarize any species characteristics. All of the bird collisions around the transmission towers happened close to the rivers between the Tatu estuary and the river. Interestingly, no bird carcasses were found in the inland areas. Although it cannot be directly concluded that the river (or water bodies) is the only reason for the bird collisions with the towers, the landscape should be an important consideration in 
bird collisions. The birds may collide with the towers because they are attracted by the water body or they prefer water activities.

In Stage 3, 4 bird carcasses were found around the transmission towers and another 3 around the wind turbines in the 52 surveys. They also varied in species. The locations of bird collisions were at the No. 10 tower, between the No. 10 and No. 12 towers, and at the No. 16 tower that they are all along the river. During the survey the researchers noticed that birds congregated in the woods below the No. 16 tower, and the tower was close to the river. Such two ecological elements, woods and water, may lead to bird collisions with the towers or their cables. There was 1 bird carcass found between the No. 10 and No. 12 towers. It was observed in the field that there were 11 cables splitting out from the No. 10 tower to the No. 11 and No. 12 towers. The power lines were distributed in a web formation, such that the birds might be easily confused and collide with the cables. Water bodies must be an important factor in bird collisions with towers, while the collision behaviors still need continuous observations and an overall analysis of the landscape in order to understand the ecological implications.

Furthermore at night, most birds in flight are unable to sense the presence of transmission towers and power lines. In areas with high density of towers and power lines, bird strikes are unavoidable. Some small, agile birds (such as the dove, grey wagtail, sparrow, and golden turtle dove) are less likely to hit transmission towers during the daytime, they are less likely to avoid such strikes at night. For medium-sized and large birds, which are less agile, or birds that have poor eyesight (such as the common moorhen, little egret, and heron), collisions presumably happen during both day and night.

\section{Wind turbines}

The wind turbines in the survey range were mainly surrounding the Chang Bin Industrial Zone and the coastal area. What was surprising was the concentrated phenomena of the bird collisions with wind turbines. There were as many as 4 different species of birds that collided with the No. 34 turbine, and another at the neighboring No. 33 turbine. These two wind turbines were also close to the river, which is similar to the phenomenon of the bird collisions with transmission towers. In the field survey, no differences were observed in the rotation speed, positioning, and environment between the No. 33 and No. 34 wind turbines and others on the same route. Thus, it was speculated that the birds would have died from collisions with the blades of wind turbines when they gathered or foraged above the freshwater river, since all of the turbines with dead birds were close to a water body. In order to discuss whether the rotation speed of the turbine was higher for the turbine with dead birds than the others, researchers recorded videos of the No. 37-38 and 33-34 turbines and compared their rotation speeds. Only an extremely small difference was found in the rotation speeds between the No. 37-38 turbines, and No. 33-34 turbines. Hence, it was deduced that the rotation speeds of all the turbines were roughly the same, so this could not explain the differences in numbers of collisions. These results indicate the need for further in-depth study of the pertinent causes of bird collisions with wind turbines in the future.

Because of structural differences, wind turbines have a different mechanism of bird strikes than transmission towers. Bird injuries and deaths are primarily caused by collisions with rotating blades, which are unpredictable from the perspective of birds because the blades do not operate with a linear motion and the rotational motion confuses birds. Bird strikes are likely to occur during both day and night when the birds 
misjudge the rotational speed of the blades. Bird carcasses of various sizes were found in this investigation. This indicated that agile birds attempted to fly across the rotating blades. Medium-sized and large birds were hit by blades because they could not easily alter their flight paths.

\section{Bird species}

If only bird collision statistics for Stages 2 and 3 were included for discussion (excluding Stage 1), the order of main bird species based on the number of bird carcasses would be egret (3), little swift (2), dove (2), heron (2), and only 1 each of other species. It has to be emphasized that there might still be other bird carcasses that were not collected. Highly abundant egret and heron are usually seen in sporadic groups near sandy beaches, riverbanks, and paddy fields. They are not flexible while flying, and thus, are very likely to collide with man-made structures around water bodies such as transmission towers or wind turbines. Little swift and dove are local common birds with great abundance, and thus, they are at an increased risk of being involved in bird collisions. If the numbers and species of bird carcasses collected in Stage 1 are included for observation, the majority was sparrows. Transmission towers included in Stage 1 were all located inland. Coincidentally, sparrows in Taiwan are terrestrial bird species and extremely abundant; thus, their collisions with transmission towers are inevitable. Transmission towers included in Stage 1 were located in a significantly different landscape compared to that in Stages 2 and 3, in which the transmission towers were located in diverse landscapes and the wind turbines were mostly located along coastlines. Different landscapes have different ecosystems and bird compositions, and thus, birds involved in collisions can be classified as terrestrial (Stage 1) and aquatic (Stages 2-3).

\section{Lights}

On the other hand, it still cannot be concluded based on the results of this study whether lights on transmission towers and wind turbines will attract approaching birds and cause collisions. Since there were plenty of street lamps in areas where the transmission towers were investigated for all the stages, with mutual interferences among different lights, the lights from the transmission towers are likely to have been made imperceptible by the high number of street lights, and will not be as attractive to birds as single flashes in dark nights of transmission towers and wind turbines. However, wind turbines are located in coastal areas where the density of street lamps in neighboring areas are relatively low, and thus, it is possible the lights from wind turbines will attract birds. The above interpretations are only speculations based on observations. The true impact of flashing lights is yet to be profoundly and systematically investigated and studied.

\section{Conclusions and suggestions}

Construction projects precipitated by the need for economic growth and technological progress should not only affect the interests of humankind, but also consider their impacts on the conservation of native species and ecological communities. Electric transmission towers and their cables are essential facilities, and wind turbines are paramount to environmental sustainability. If safety, convenience, and 
conservation are all taken into account in engineering construction, we will be able to build more balance between construction development and ecological conservation. Hence, the goal of this project is to integrate conservation into engineering construction.

A total of 21 bird carcasses were collected during this research. Twelve were found around transmission towers and nine around wind turbines. Based on the locations of transmission towers and wind turbines where the carcasses were found, our speculations are summarized below.

(1) All bird carcasses were resident land birds; no seabirds or migrants were found. Nevertheless, the research location was the estuary of the Dadu River in a waterfront area, which is a hot spot for birds during migration. It was unusual that no seabird or migrant carcasses were found. The small numbers of seabirds in Taiwan's coastal areas could be a possible explanation for this occurrence

(2) All transmission towers and wind turbines where the bird carcasses were found were near freshwater bodies, which were the preferred water bodies for most land birds. The probability of bird collision events was hence increased.

(3) We expected bird collision events for migrants in this area. However, a relatively small number of migrants were observed relative to that of resident land birds. Their stopover is only short-term. Furthermore, bird carcasses might have been removed by scavengers, such as wild dogs, or blown away by the strong winds. Therefore, the chance of finding them was significantly smaller than that of finding bird carcasses of land birds.

(4) Seabirds spend most of their time at sea. When they approach land, they typically fly low over the water or stay on the shore and are unlikely to hit transmission towers. Their flying heights are also likely to minimize the chance of strikes with wind turbines. Consequently, no sea bird carcasses were found. According to this study, onshore wind turbines should not cause injury or death to sea birds.

On the other hand, bird carcasses were concentrated around certain wind turbines. As many as 4 bird carcasses were found at the No. 34 turbine, 2 at the No. 21 turbine, another 2 at the No. 38 turbine, and 1 at the No. 33 turbine. None were found at the other turbines. The areas near the No. 33 turbine and the No. 34 turbine should be regarded as hot spots for bird collisions. However, it may seem arbitrary to affirm that the above wind turbines were hot spots for collisions since the survey was conducted weekly. It also cannot be determined whether there were any bird collisions between two surveys. Meanwhile, it was impossible to determine whether bird carcasses would be carried outside of the observation range by strong winds after collision with a turbine blade. However, the concentration phenomenon cannot be ignored. It can only be said that there is nothing statistically significant about the rotation speed and the positioning of the wind turbines. The more significant factor was that the No. 33, 34, and 21 wind turbines were all close to freshwater bodies, and their high probabilities of bird collisions were similar to those of the towers. Therefore, for the towers and wind turbines, being close to a water body is an important factor in collisions. Despite the variety of species, the aggregation of bird carcasses was very high. This result is important for engineering design. Field observations must be sustained for a long time to explore the reasons for such a high concentration, which is costly in terms of labor. However, with the planned survey in this study, some of the turbines were already chosen as our focus. Similarly, continuous observations could be carried out around transmission towers or wind turbines with concentrated bird collisions, and there would 
be real-time witnessed bird collisions at the turbines. This would be beneficial to bird conservation.

There were 31 towers in this survey. Stage 2 and Stage 3 lasted 14 months in total, during which a total of 6 bird carcasses were found. There are 21,844 towers in Taiwan. It is expected that the probability of bird collisions would be higher in mountainous areas than in the studied area, whereas that in urban areas would be lower. It is hypothesized that the bird collision frequency of the studied area is typical for Taiwan. If the situation of bird collisions with towers is similar to that of this area, and taking further consideration of the about 70-meter height of each tower in Taiwan and the total number of transmission towers according to Taiwan Power Inc. (www.taipower.com.tw/news/new198.htm), the annual bird deaths from collisions with transmission towers in Taiwan would be roughly estimated to be at least:

$$
\frac{7}{31} \times \frac{12}{14} \times 21884 \cong 4236
$$

Among these deaths, even the collision situations of the rare, conserved, and important species are unknown; they may have significant effects on the populations of these species.

There were a total of 9 bird carcasses found around the 35 wind turbines, while only about 200 wind turbines existed in Taiwan. Thus, the average annual bird deaths from collisions with wind turbine blades must be at least:

$$
\frac{9}{35} \times \frac{12}{14} \times 200 \cong 44
$$

However, if a turbine is located on the migration route of birds, the number of bird collisions must be higher. Besides, the number of bird collisions counted in this survey was lower than the actual number, which could be 2-3 times higher. In particular, bird carcasses may have been carried far away by wind after collisions with wind turbines and could not be collected by the researchers. Therefore, bird casualties from wind turbines may need more attention and could be much higher than what was estimated in this study.

After studying the relationships between the mechanisms of bird strikes with transmission towers and wind turbines; bird species; and geographic locations of artificial facilities, the following feasible conservation measures are proposed.

(1) Complete ecological surveys should be conducted before building transmission towers or onshore wind turbine generator systems. In addition to allowing for the ecological characteristics of resident birds, possible flight paths of migrants should also be considered. If migration paths can be avoided, it should reduce the incidence of migrant bird collisions.

(2) Because it is possible for various types of land birds to collide with transmission towers and wind turbines, if these facilities are built in the habitats of rare or endangered species, special designs should be implemented to avoid bird strike events to further decrease injuries and mortality of rare species. It is known from this study that towers should be far away from water bodies in order to avoid bird collisions, which is 
particularly important for areas of ecological abundance. This reduces the chance of birds getting close to the towers. Avoiding sitting wind turbines along migration routes or in areas where birds congregate could reduce the chances of bird collisions with the turbines.

(3) In the future, Taiwan will devote major efforts to the development of offshore wind turbines. Even sea bird may dodge the wind turbine (Desholm and Kahlert, 2005), such facilities are still likely to lead to collisions affecting seabirds and migrants (Marques et al., 2014). The difficulty in conducting surveys, however, will be the biggest obstacle to research. This issue requires further in-depth study. Furthermore, ecological issues should be of utmost consideration when designing and building offshore wind turbines.

Acknowledgements. This research is sponsored by the Ministry of Science and Technology of Taiwan, ROC (Grant no. 100-2221-E-507-006).

\section{REFERENCES}

[1] Avery, M., Springer, P. F., Cassel, J. F. (1976): The effects of a tall tower on nocturnal bird migration - A portable ceilometer study. - Auk 93:281-291.

[2] Ball, L.G., Zyskowski, K., Griselda, E. S. (1995): Recent bird mortality at a Topeka television tower. - Kansas Ornithological Society Bulletin 46:33-35.

[3] Banks, R. C. (1979): Human-related mortality of birds in the United States. U.S. Department of Interior, Fish and Wildlife Service. - Special Scientific Report - Wildlife No. 215.

[4] Bevanger, K., Brøseth, H. (2004): Impact of power lines on bird mortality in a subalpine area. - Animal Biodiversity and Conservation 27( 2): 67-77.

[5] Cochran, W. W., Graber, R. R. (1958): Attraction of nocturnal migrants by lights on a television tower. - Wilson Bulletin 70:378-380.

[6] Crawford, R. C., Engstrom, R. T. (2000): Lights, towers, and avian mortality: where is the science? - In: Transcripts of Proceedings of the Workshop on Avian Mortality at Communications Towers, August 11, 1999. Cornell University, Ithaca, NY.

[7] Crawford, R. L., Engstrom, R. T. (2001) Characteristics of avian mortality at a north Florida television tower: a 29-year study. - Journal Field Ornithology 72: 380-388.

[8] Desholm, M., Kahlert, J. (2005): Avian collision risk at an offshore windfarm. Biological Letters 1: 296-298.

[9] Evans, W. R., Akashi, Y., Altman, N. S., Manville II. A. M. (2007): Response of nightmigrating songbirds in cloud to colored and flashing light. - North American Birds 60:476-488.

[10] Gauthreaux, S. A. Jr., Belser, C. G. (2006): Effects of artificial night lighting on migrating birds. - In: Ecological Consequences of Artificial Night Lighting. Rich, C. and Longcore, T. (eds.), pp. 67-93. Island Press, Covelo, California.

[11] Gehring, J., Kerlinger, P., Manville, II. A. M. (2009): Communication towers, lights, and birds: successful methods of reducing the frequency of avian collisions. - Ecological Applications 19(2):505-514.

[12] Graber, R. R. (1968): Nocturnal migration in Illinois - Different points of view. - Wilson Bulletin 80:36-71.

[13] Kerlinger, P. (2000): An assessment of the impacts of Green Mountain Power Corporation's Searsburg, Vermont. wind power facility on breeding and migrating birds. In: Proceedings of the National Wind Coordinating Meeting, San Diego, CA. 1998. 
[14] Larkin, R. P., Frase, B. A. (1988): Circular paths of birds flying near a broadcasting tower in cloud. - Journal of Comparative Psychology 102:90-93.

[15] Longcore, T., Rich, C., Gauthreaux Jr. S. A. (2008): Height, Guy cables, and Steadyburning Lights Increase Hazard of Communication Towers to Nocturnal Migrants: A Review and Meta-analysis. - Auk 125(2):485-492.

[16] Marques, A. T., Batalha, H., Rodrigues, S., Costa, H., Pereira, M. J. R., Fonseca, C., Mascarenhas, M., Bernardino, J. (2014): Understanding bird collisions at wind farms: an updated review on the causes and possible mitigation strategies. - Biological Conservation 179: 40-52.

[17] Shi, Y. Y., Cheng, S. Y. (2008): The impact of wind farms on the coast of Changhua on the flock and activity types of shorebirds. - Journal of Environment and Ecology National University of Tainan 1(1):47-64.

[18] Shi, Y. Y., Yen, C. F., Chen, B. H., Cheng, S. Y. (2008): Effect of coastal wind turbines on bird assemblages using Lun Mei wind farm in Chang Bin Industrial Zone as an example. - In: Seventh Cross-Strait Symposium on Birds 26-27.

[19] Towerkill.com (www.towerkill.com)

[20] Wilson, E. O. (1989): Threats to biodiversity. - Scientific American 261(3):108-116. 